\title{
Acute Intracranial Hypertension During Pregnancy: Special Considerations and Management Adjustments
}

\author{
Daniel Agustin Godoy ${ }^{1,2^{*}}$, Chiara Robba ${ }^{3}$, Wellingson Silva Paiva ${ }^{4}$ and Alejandro A. Rabinstein ${ }^{5}$
}

C 2021 Springer Science+Business Media, LLC, part of Springer Nature and Neurocritical Care Society

\begin{abstract}
Pregnancy is associated with a number of pathophysiological changes (including modification of vascular resistance, increased vascular permeability, and coagulative disorders) that can lead to specific (eclampsia, preeclampsia) or not specific (intracranial hemorrhage) neurological complications. In addition to these disorders, pregnancy can affect numerous preexisting neurologic conditions, including epilepsy, brain tumors, and intracerebral bleeding from cerebral aneurysm or arteriovenous malformations. Intracranial complications related to pregnancy can expose patients to a high risk of intracranial hypertension (IHT). Unfortunately, at present, the therapeutic measures that are generally adopted for the control of elevated intracranial pressure (ICP) in the general population have not been examined in pregnant patients, and their efficacy and safety for the mother and the fetus is still unknown. In addition, no specific guidelines for the application of the staircase approach, including escalating treatments with increasing intensity of level, for the management of IHT exist for this population. Although some of basic measures can be considered safe even in pregnant patients (management of stable hemodynamic and respiratory function, optimization of systemic physiology), some other interventions, such as hyperventilation, osmotic therapy, hypothermia, barbiturates, and decompressive craniectomy, can lead to specific concerns for the safety of both mother and fetus. The aim of this review is to summarize the neurological pathophysiological changes occurring during pregnancy and explore the effects of the possible therapeutic interventions applied to the general population for the management of IHT during pregnancy, taking into consideration ethical and clinical concerns as well as the decision for the timing of treatment and delivery.
\end{abstract}

Keywords: Intracranial pressure, Cerebral perfusion pressure, Pregnancy, Intracranial hypertension, Cerebral autoregulation, Intracranial pressure monitoring

\section{Introduction}

Intracranial hypertension (IHT) may occur as a consequence of intracranial pathologies-such as cerebral edema, trauma, and intracranial hemorrhage with consequent loss of the usual balance between the different intracranial components-as well as extracranial causes, such as abdominal or thoracic hypertension [1-3]. IHT etiology is multifactorial, and its consequences are fatal

\footnotetext{
*Correspondence: dagodoytorres@yahoo.com.ar

${ }^{1}$ Neurointensive Care Unit, Sanatorio Pasteur, Catamarca, Argentina

Full list of author information is available at the end of the article
}

if not promptly recognized and managed $[1,2]$. Because IHT represents a medical-surgical emergency, its proper management must be solidly supported by a thorough evaluation of the factors contributing to its pathogenesis $[1,2]$.

It is well known that pregnancy can be complicated by a number of neurocritical care pathologies that expose pregnant patients to a high risk of neurological complications and IHT $[4,5]$. Unfortunately, to date, none of the therapeutic measures adopted for the control of elevated intracranial pressure (ICP) have been tested in terms of efficacy and safety for the mother and the fetus during

\section{国


pregnancy. Furthermore, no specific guidelines for the application of the algorithmic approach of escalating levels of management for IHT exist for this population. Only a comprehensive best practices statement made a number of expert-consensus-based recommendations in pregnant patients with stroke [6].

These gaps are particularly problematic because some of the treatments for IHT (such as hyperventilation, hypothermia, barbiturates) may be hazardous during pregnancy.

The aim of this review is to analyze the unique aspects of IHT during pregnancy and to discuss the relative advantages and disadvantages of various therapeutic options in this situation.

\section{Physiological Changes Induced by Pregnancy Systemic}

Pregnancy causes profound hormonal, enzymatic, and metabolic changes that affect the physiology of all the organs and systems of the body (Fig. 1) [7, 8]. Progesterone, relaxin, cortisol, and adrenergic monoamines are the main chemical mediators. Around the eighth week of gestation, the growing uterus begins to exert mechanical pressure on the abdominal compartment $[7,8]$. Meanwhile, the development of the vascular network between the placenta and the fetus results in a hyperdynamic maternal circulation and increased metabolic demands $[7,8]$.

\section{Central Nervous System \\ Cerebral Circulation}

Pregnancy results in an up to $40-50 \%$ increase in circulating plasma volume and cardiac output and a concomitant compensatory decrease in systemic vascular resistance to maintain a healthy blood pressure. Although other organs can tolerate the resulting increase in perfusion, such a change would result in major deleterious consequences to the brain. The brain must regulate cerebral blood flow $(\mathrm{CBF})$ within a narrow range to maintain its normal function and to prevent increased ICP. Thus, multiple adaptations unique to the brain occur during pregnancy to preserve a relatively constant CBF despite a hyperdynamic systemic circulation $[9,10]$ :

- Cerebral arteries must adapt to counteract the effect of vasoconstrictors released into the systemic circulation during late gestation. The precise mechanisms for this adaptation are unclear but may involve endothelial changes favoring a vasodilatory response [10]. The autoregulatory range may

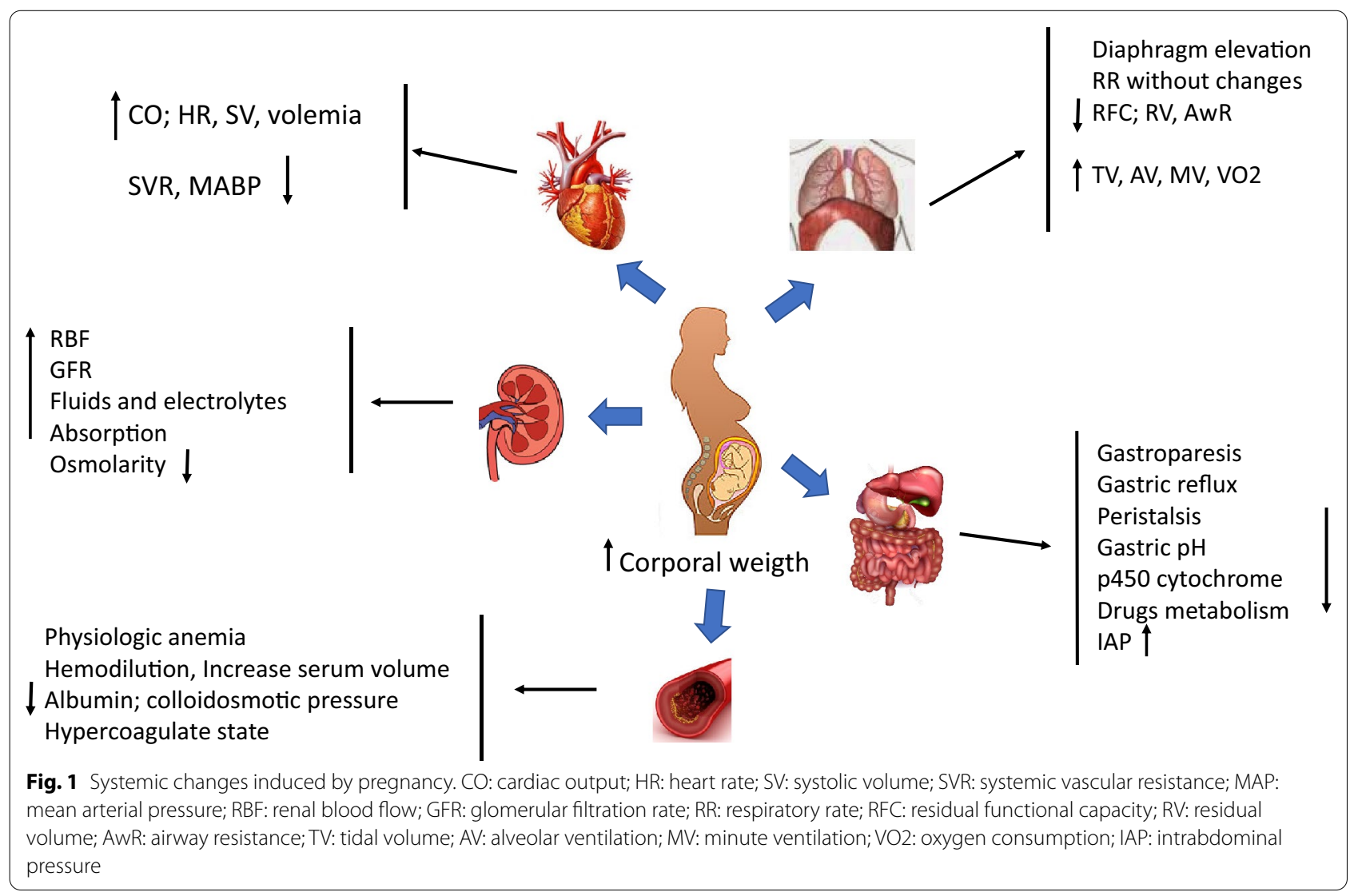


widen during pregnancy, with a decreased lower limit and increased upper limit of autoregulation, thereby enhancing cerebral tolerance to hypotension or hypertension (Fig. 2) [11, 12]. Failure of these autoregulatory adjustments may play a role in the development of preeclampsia [13].

- Structural changes have been reported in cerebral arterioles, but not in pial vessels, in pregnant rats. Those changes consist of hypotrophic remodeling, with luminal enlargement and thinning of the arteriolar wall, and by decreasing distal vascular resistance, they can help accommodate increased flow to sustain the greater metabolic demands of some brain structures [10, 14]. However, it has been conjectured that this remodeling of small vessels can render them more susceptible to injury from acute hypertension [10].

- Impact of preeclampsia/eclampsia on cerebral circulation: During pregnancy, cerebral circulation undergoes structural and functional adaptations aimed at maintaining intracranial homeostasis [10-14]. These modifications tend to maintain the permeability of the blood-brain barrier (BBB) and counteract the dominant vasoconstrictor state, which especially occurs in the last trimester of gestation [10-14]. Cerebral autoregulation becomes adjusted to the circulatory changes and dominant vasoconstriction [1014]. Posterior reversible encephalopathy syndrome related to preeclampsia/eclampsia is characterized by endothelial dysfunction, which compromises cerebral autoregulation [15]. As a consequence, increases in mean arterial pressure (MAP) translate into increased capillary hydrostatic pressure and BBB permeability, resulting in vasogenic edema, microbleeds, and inflammation [15]. The mechanisms involved are variable and complex; standing out among them are

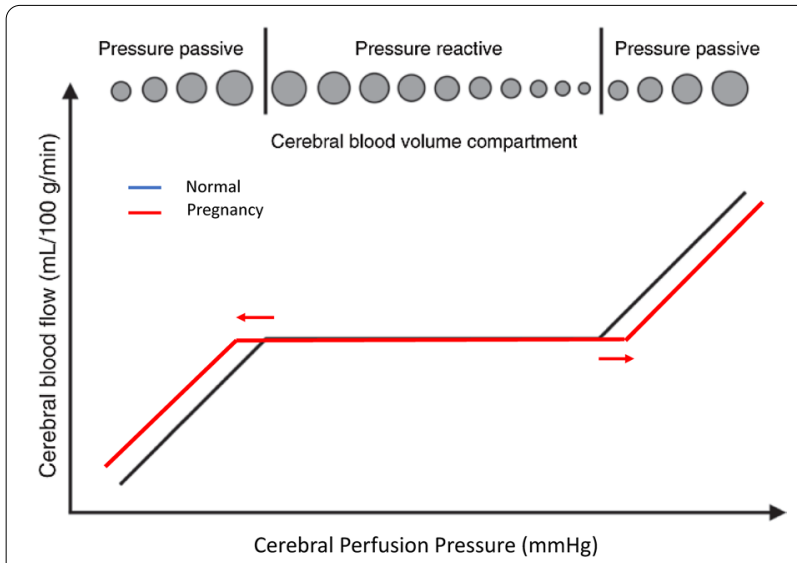

Fig. 2 Changes in cerebrovascular autoregulation during pregnancy hyperperfusion, alterations of the factors that oppose the vasoconstrictor state, increases in the electrical conductivity of the $\mathrm{BBB}$, and decreases or blocking of the mediators (sFlt1) that keep the permeability of the $\mathrm{BBB}$ intact by counteracting the effects of the vascular endothelial growth factor [15].

\section{BBB}

$\mathrm{BBB}$ permeability remains mostly unchanged during normal pregnancy despite increased circulating levels of factors that augment vascular permeability (such as vascular endothelial growth factor and placental growth factor) [16]. Disruption of the BBB resulting in increased permeability has been observed in animal models of preeclampsia [15, 17], but whether this mechanism contributes to the pathogenesis of the disease in humans remains a matter of debate [18]. Overexpression of aquaporin 4 is known to occur during the second half of gestation and could affect the formation and resolution of brain edema [19].

\section{Seizure Threshold}

Pregnancy induces a state of neuronal hyperexcitability, thereby increasing susceptibility to seizures $[9,10]$. This phenomenon is more pronounced during the latter part of gestation. Its mechanisms are not well elucidated, but downregulation of $\gamma$-aminobutyric acid (GABA) A receptors and upregulation of aquaporin 4 may be important contributors $[9,10]$.

\section{Subarachnoid Space and Cerebrospinal Fluid}

From week 16 of gestation, the gravid uterus and the intraabdominal pressure increase and accentuate aortocaval compression $[7,8]$. The resulting congestion of epidural venous plexuses from the thoracic to the sacral levels leads to compression of the subarachnoid space and reduction in thecal cerebrospinal fluid (CSF) volume [20]. These changes may also affect the volume and distribution of intracranial CSF. Additionally, CSF becomes more alkaline during pregnancy, with lower $\mathrm{CO}_{2}$ pressure and protein content $[7,8]$.

The changes noted in the volume of the CSF of the spinal space increase the sensitivity of anesthetics delivered regionally (epidural); at the same time, they may decrease the intracranial compliance, thereby potentially increasing the risk of IHT [21-23]. There are no reports suggesting any relationship between changes in CSF volume and development of hydrocephalus. The $\mathrm{pH}$ of CSF is alkalinized during the second and third trimesters of pregnancy; together with a decrease in $\mathrm{CO}_{2}$ levels, both adaptive phenomena follow the systemic physiological changes [21-23]. These modifications can sometimes 
trigger neurovegetative symptoms. Additionally, these changes may decrease the seizure threshold because it is associated with a decrease in GABA levels. CSF protein levels also decrease in the aforementioned gestation periods, thereby increasing the concentrations of anesthetic drugs, especially in their nonionized form [21-23].

\section{Pharmacokinetic Changes}

Pregnancy results in increased volumes of distribution (because of larger body mass and expansion of plasma volume) and augmented renal clearance (because of increased renal blood flow and glomerular filtration rate) [24]. Concomitant increases in volume of distribution and clearance can affect the half-lives of medications in opposing directions. As a general rule, a larger volume of distribution will diminish the effect to first drug boluses, whereas augmented clearance will lower serum concentrations of the drug during a steady state. Plasma protein concentrations decrease after the second trimester, and drug-binding capacity is consequently reduced by $20-30 \%$ by the end of gestation [24]. Meanwhile, the effect of pregnancy across hepatic enzymes is variable [24]. Pharmacokinetics studies during pregnancy have revealed consistent results for various classes of drugs, and they can be used to guide drug administration [25].

These pharmacokinetic changes may result in clinically significant consequences. Serum concentration of highly protein-bound medications (such as midazolam, phenytoin, valproic acid) should be expected to be higher late in pregnancy. Instead, serum concentrations of renally cleared drugs (such as heparin, opiates, levetiracetam, aminoglycosides) are likely to be lower than expected [8, $24,25]$. Drugs predominantly metabolized by the liver (such as barbiturates) can be variably affected and therefore require careful monitoring of trough concentrations $[8,24,25]$.

Pharmacokinetic considerations must also include the fetus $[8,24,25]$. Drugs that can cross the placental barrier can reach higher concentrations in the fetal circulation because of the lower metabolic capacity and volume of distribution of the fetus. This can be particularly dangerous when administering sedatives and other respiratory depressants. Thus, drug administration to critically ill pregnant patients should optimally be coordinated by a multidisciplinary team that includes pharmacists and obstetricians.

\section{Causes of IHT During Pregnancy}

The prevalence and causes of IHT during pregnancy have not been evaluated in detail. It can be caused by decompensation of a preexisting pathology (e.g., tumor) or by acute disease (e.g., trauma or vascular events) [7, 8, 26]. A summary of the different etiologies of IHT and their mechanisms are presented in Table 1.

The exact incidence of IHT during pregnancy is unknown. The median age of pregnant women with neurological/neurosurgical complications ranges between 20 and 30 years $[4,5]$. Conditions causing IHT during

Table 1 Causes and mechanisms of production of intracranial hypertension during pregnancy

\begin{tabular}{|c|c|}
\hline Etiology of intracranial hypertension & Mechanism of production \\
\hline Tumors & $\begin{array}{l}\text { Mass lesion } \\
\text { Vasogenic edema }\end{array}$ \\
\hline Traumatic Brain Injury with or without polytrauma & $\begin{array}{l}\text { Mass lesions } \\
\text { Vasogenic, cytotoxic edema } \\
\text { Extracranial causes (intratho- } \\
\text { racic or intrabdominal } \\
\text { hypertension) } \\
\text { Secondary insults (hyper- } \\
\text { capnia) }\end{array}$ \\
\hline Idiopathic Intracranial Hypertension & Unclear \\
\hline $\begin{array}{l}\text { Preeclampsia } \\
\text { Posterior Reversible Encephalopathy Syndrome }\end{array}$ & Vasogenic edema \\
\hline $\begin{array}{l}\text { Cerebrovascular Diseases } \\
\text { Spontaneous Intracerebral Hemorrhage } \\
\text { Secondary Intracerebral Hemorrhage } \\
\text { Arteriovenous Malformations Rupture } \\
\text { Subarachnoid Hemorrhage } \\
\text { Cerebral venous Thrombosis }\end{array}$ & $\begin{array}{l}\text { Mass effect, Vasogenic edema } \\
\text { Cytotoxic edema, Hydro- } \\
\text { cephalus, CSF circulation } \\
\text { alteration }\end{array}$ \\
\hline $\begin{array}{l}\text { CNS infections } \\
\text { Encephalitis/Meningitis } \\
\text { Brain Abscess }\end{array}$ & $\begin{array}{l}\text { Vasogenic, cytotoxic edema } \\
\text { Mass lesion, Vasogenic edema }\end{array}$ \\
\hline Acute fatty liver & Vasogenic, cytotoxic edema \\
\hline Shunt Malfunction & Hydrocephalus \\
\hline
\end{tabular}


pregnancy are more prevalent in the second and third trimesters $[4,5]$. The most common causes of IHT in pregnancy are preeclampsia (2-8\%), head trauma $(0.5-6 \%)$, ischemic or hemorrhagic stroke (10-34 cases per 100,000 pregnancies), and tumor complications (3.2-3.6 cases per million live births) and are favored by increased vasculature associated with high levels of estrogen and progesterone $[4,5]$. Stroke is more frequent in the intrapartum $(40 \%)$ and postpartum $(50 \%)$ periods $[4,5]$. Other risk factors for the development of IHT are arterial hypertension, coagulopathy, and cardiomyopathy $[4,5]$.

\section{Definition of IHT During Pregnancy}

Traditionally, IHT is defined by sustained ICP greater than $20 \mathrm{~mm} \mathrm{Hg}[1,2]$. The latest version of the traumatic brain injury guidelines modified the threshold to $22 \mathrm{~mm}$ $\mathrm{Hg}$ [27].

Ideally, IHT should be evaluated under consideration of the context in which it develops $[28,29]$. However, there is insufficient information on the physiological range of ICP during pregnancy or on what should be the optimal definition of IHT in this setting.

\section{IHT Evaluation During Pregnancy}

The clinical presentation of IHT, such as headache and vomiting, is often nonspecific and unreliable, whereas the classic Cushing's triad (arterial hypertension, irregular breathing, bradycardia) is a late expression of IHT when brain herniation is already occurring [1]. No differences in terms of clinical presentation have been observed between the pregnant and not pregnant population.

Papilledema is most prominent when IHT develops slowly, and its absence does not exclude the presence of IHT. Pupillary asymmetry is not a reliable marker of IHT; in fact, only $33 \%$ of individuals with pupillary asymmetry greater than $3 \mathrm{~mm}$ have ipsilateral focal lesions [30]. The presence of a clinical picture compatible with cerebral herniation (abnormal motor posturing, depression of consciousness, nonreactive mydriasis) demands immediate and aggressive therapy even before neuroimaging and ICP monitoring.

Computed tomography $(\mathrm{CT})$ with adequate maternal protection is the neuroimaging modality of choice in pregnant patients with suspected acute brain injury. Although the fetus is more susceptible to the risks from radiation exposure, the radiation dose of a head CT scan is less than 0.5 rads [31]. Fetal abnormalities, growth retardation, and loss of pregnancy have not been demonstrated with exposures less than 5 rads [31]. The exact dose of fetal radiation exposure from noncontrast head CT is between 0.001 and $0.01 \mathrm{mGy}(1 \mathrm{mGy}=0.1 \mathrm{rad})$, which is well below the dose considered safe (5 mGy) [31, 32]. In addition, the use of intravenous contrast is not

contraindicated in the case of life-threatening maternal illness [31, 32]. Noncontrast MRI is a safe option during pregnancy because of the absence of maternal-fetal exposure to ionizing radiation [31, 32]. MRI $(1.5$ or $3.0 \mathrm{~T})$ does not increase the risk of adverse fetal outcomes at any trimester of the pregnancy [31,32]. Gadolinium is not recommended because it may increase risk of fetal adverse effects, especially during the first trimester [31, 32].

Scans should be reviewed systematically for the presence of space-occupying lesions associated with parenchyma distortion or displacement, hydrocephalus, midline shift, effacement of basal cisterns, and sulci over the cerebral convexities [33].

A recent diagnostic rule based on clinical and CT data was developed to predict IHT (Table 2) [34]. When IHT was defined as ICP $>22 \mathrm{~mm} \mathrm{Hg}$, the sensitivity and specificity of this diagnostic rule were $93.9 \%$ and $42.3 \%$, respectively; $100 \%$ sensitivity was reached when IHT was defined as ICP $>30 \mathrm{~mm} \mathrm{Hg}$ [34]. This rule should be similarly applicable to pregnant patients.

Noninvasive methods for ICP evaluation (transcranial Doppler, pupillometry, optic nerve sheath diameter) are interesting alternatives during pregnancy; however, they remain investigational and should not be considered sufficiently reliable to guide IHT management currently [35].

The indications for invasive ICP monitoring, as well as the type of device to be used, should not differ from those in nonpregnant patients.

\section{Approach to IHT Management During Pregnancy}

Usual treatment measures for IHT lack solid scientific evidence, and this is even more so the case during pregnancy [36, 37]. However, it is a widely accepted principle that measures for ICP treatment should be implemented in a stepwise manner, from the least to the most likely to cause adverse effects to the mother and the fetus $[1,2]$. This stepwise approach is a proposal to adapt existing algorithms in nonpregnant women to pregnant women on the basis of known toxicities of different therapies. Yet

\section{Table 2 Clinical-radiological diagnostic rule for the diag- nosis of IHT}

\section{Major criteria}

Compressed basal cisterns

Midline Shift $>5 \mathrm{~mm}$

Nonevacuated mass lesion

The rule was considered positive when one major criterion or two or more minor criteria were present [28]

\section{Minor criteria}

Motor GCS $\leq 4$ Pupillary asymmetry

Abnormal pupillary reactivity Marshall tomography classification type II 
it is important to keep in mind that this approach has not been specifically studied for efficacy or fetal safety.

The measures must be "additive," meaning that when we decide to implement one, we should not abandon the previous one. It is also important to take some time (often approximately $30 \mathrm{~min}$ ) to evaluate the effectiveness of the therapy before proceeding to the next step [1, $2,38]$.

At each step, clinicians should consider the possibility of repeating neuroimaging, especially when there is an abrupt change in the clinical picture or in ICP levels without a clear explanation to justify it [2, 38] (Fig. 3).

\section{First-line Therapies}

\section{General Measurements}

The first steps should be directed to determine the cause of the IHT, preventing early complications and maintaining cerebral functions [1, 2]. First-level therapies (Fig. 3) include general measures such as placing the head in a neutral position (neither flexed nor extended) aligned with the rest of the body and raised 30 degrees above the horizontal [1, 2, 38]. This position helps prevent microaspirations of gastric contents and may reduce the risk of pneumonia, which is of particular importance in pregnant patients who have increased intrabdominal pressure and higher risk of aspiration [2, 7, 39].

Head elevation should be maintained even if left lateral decubitus is necessary to alleviate the hemodynamic effects from compression of the uterus on the aorta and inferior vena cava. Clinicians should not forget to check orotracheal tube restraints and cervical collars to ensure that they are not compressing the jugular veins and restricting venous outflow [2, 39].

Physiological neuroprotection is a set of measures aimed at maintaining physiological homeostasis, which if altered, can negatively affect ICP [2, 27, 39]. These measures should also be applied when IHT occurs during pregnancy (Fig. 4).

Physiological neuroprotection aims at maintaining homeostasis of crucial physiological variables to avoid secondary cerebral insults. The following goals are extrapolated from nonpregnant women, adapted to this situation:

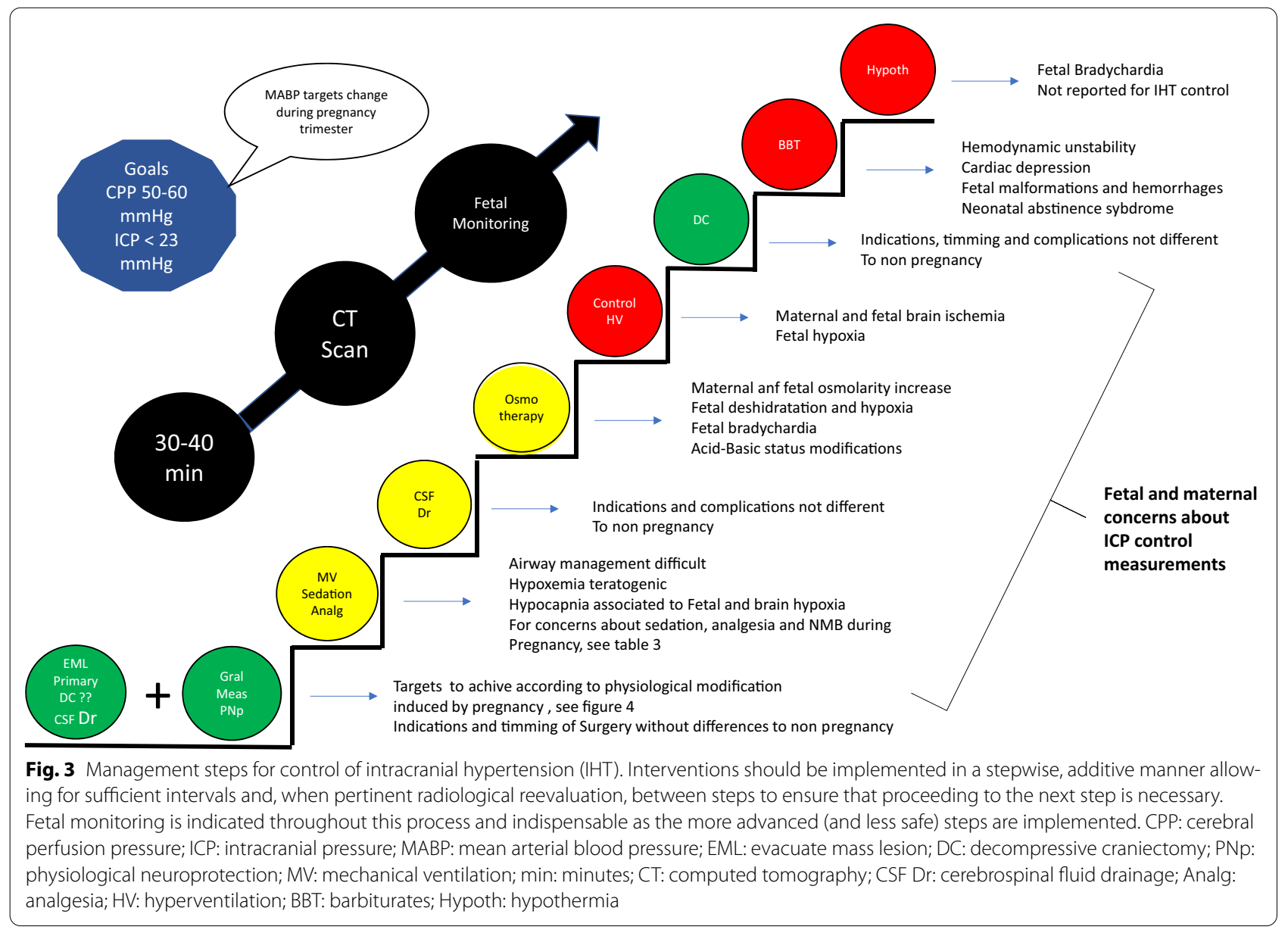




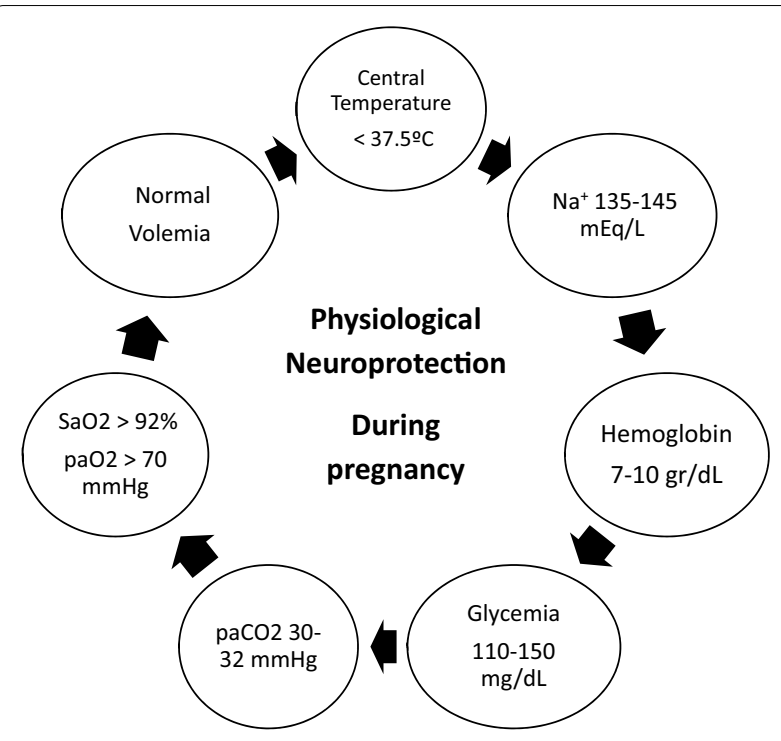

Fig. 4 Physiological neuroprotection. $\mathrm{Na}^{+}$: serum sodium

1. Central temperature: Pregnancy increases the metabolism activity of the body, which in turns increases the core temperature between 0.3 and $0.4{ }^{\circ} \mathrm{C}[7,8]$. Hyperthermia favors the release of neurotoxic mediators, increases BBB permeability, and causes cerebral vasodilation, all of which can increase ICP [2, 39].

(a) Goal: $<37.5^{\circ} \mathrm{C}$.

2. Intravascular volume: Pregnancy increases intravascular volume by $40-50 \%$ [7, 8]. Hypovolemia should be avoided because it may lower mean arterial blood pressure (MABP) and cerebral perfusion pressure (CPP).

3. Normoxemia: Both hypoxemia and arterial hypotension are the secondary insults with the greatest negative impact on the mother and the fetus because they cause tissue hypoxia and decrease CBF [1-4]. During pregnancy, arterial oxygen pressure $\left(\mathrm{paO}_{2}\right)$ increases to $103-107 \mathrm{~mm} \mathrm{Hg}$ as a consequence of the increase in alveolar ventilation.

(a) Goal: maintain arterial oxygen saturation $\left(\mathrm{SaO}_{2}\right)>92 \%$ or $\mathrm{paO}_{2}>80 \mathrm{~mm} \mathrm{Hg}[7,8]$.

4. Normocapnia: Pregnancy increases minute ventilation; therefore, the arterial pressure of carbon dioxide $\left(\mathrm{PaCO}_{2}\right)$ serum concentration falls to approximately 30-32 mm $\mathrm{Hg}[7,8]$. Vasomotor reactivity of the cerebral circulation to $\mathrm{CO}_{2}$ is maintained thanks to adaptation to the lower $\mathrm{PaCO}_{2}$ concentration, but excessive hypocapnia can result in ischemia from cerebral vasoconstriction, and hypercapnia can increase ICP secondary to cerebral vasodilation $[4,5]$.

(a) Goal: maintain $\mathrm{PaCO}_{2}$ at $30-32 \mathrm{~mm} \mathrm{Hg}[4,5]$.
5. Natremia and osmolality: Pregnancy causes a decrease in osmolarity, mainly because of an increase in blood volume and hemodilution [7, 8]. Hyponatremia and severe hypoosmolality should be avoided in patients with or at risk of brain edema.

(a) Goal: maintain $\mathrm{Na}^{+}$levels between 135 and $145 \mathrm{mEq} / \mathrm{L}[2,39]$.

6. Hemoglobin: Pregnancy causes a state of physiological anemia, with hemoglobin values at approximately $12 \mathrm{~g} / \mathrm{dL}[7,8]$. The hemoglobin dissociation curve shifts to the right $[7,8]$.

(a) Goal: avoid hemoglobin levels $<7 \mathrm{~g} / \mathrm{dL}$ to avoid alterations in systemic oxygen transport and cerebral tissue hypoxia $[2,39]$.

7. Glycemia: Hypoglycemia is deleterious for the injured brain and for the fetus [40]. Severe hyperglycemia may contribute to inflammation, thrombosis, and brain edema [40]. Pregnancy increases blood glucose levels because of insulin resistance caused by placental lactogen $[7,8]$. The injured brain presents a state of increased glucose consumption (hyperglycolysis) and becomes dependent on systemic glucose delivery [40]. Glucose levels less than $110 \mathrm{mg} / \mathrm{dL}$ have been associated with nonischemic metabolic crises [41].

(a) Goal: maintain serum glucose concentration between 110 and $150 \mathrm{mg} / \mathrm{dL}$ [2, 39].

\section{Airway and Mechanical Ventilation}

As the uterus grows, it eventually causes diaphragmatic elevation, decreasing residual lung volume and functional residual capacity $[7,8]$. Compensatory increases in minute ventilation may produce mild hypocapnia. Susceptibility to hypoxemia may be heightened because of the reduction in lung volume. Tracheal intubation may be more challenging because of structural airway changes $[42,43]$. The mucosa of the upper respiratory tract becomes more vascular and edematous, leading to increased risk of airway bleeding and swelling [42, 43]. Consequently, the Mallampati score rises as pregnancy progresses as well as during labor and delivery $[42,43]$. Progesterone reduces lower esophageal sphincter tone, resulting in gastric reflux, and a delay in gastric emptying occurs during painful labor and after opioid administration. Intubation and mechanical ventilation may be necessary to preserve airway patency and to maintain adequate ventilation and oxygenation in pregnant patients with acute brain injury $[1,2,27]$. Profound and prolonged hypoxemia is teratogenic and can even be fatal to the fetus $[44,45]$. Hypocapnia beyond the physiological changes inherent to pregnancy $(<30 \mathrm{~mm} \mathrm{Hg})$ causes uteroplacental vasoconstriction with the risk of fetal ischemia, whereas hypercapnia can cause respiratory acidosis and fetal myocardial depression [46]. On the other 
hand, chronic hypercapnia is associated with fetal cardiac malformations [47]. The optimal way to ventilate a pregnant woman is controversial, especially in terms of whether to use the protective lung strategy $[48,49]$. In general, and according to recent evidence, it seems prudent to start mechanical ventilation with a controlled mode, tidal volumes between 6 and $8 \mathrm{~mL} / \mathrm{kg}$, minimum respiratory rates to ensure adequate minute ventilation (with a target $\mathrm{PaCO}_{2}$ of $30-32 \mathrm{~mm} \mathrm{Hg}$ ), and inspirated fraction of oxygen $\left(\mathrm{FiO}_{2}\right)$ and positive end expiratory pressure (PEEP) necessary to achieve $\mathrm{paO}_{2}>70 \mathrm{~mm} \mathrm{Hg}$ and $\mathrm{SaO}_{2}>92 \%$. To prevent volutrauma, plateau pressure should be kept at $<24 \mathrm{~cm} \mathrm{H}_{2} \mathrm{O}$ and driving pressure at $<13 \mathrm{~cm} \mathrm{H}_{2} \mathrm{O}[48-50]$.

\section{Hemodynamic Management}

Maintaining adequate CPP is vital [1, 2, 38]. Regardless of the type of injury, arterial hypotension should be avoided and quickly corrected [1, 2, 38, 50]. Pregnant patients typically have low blood pressure during the first two trimesters and may become hypertensive during the third trimester. Therefore, the CPP target may need to vary depending on the stage of gestation. CPP depends on MABP and ICP. During normal pregnancy, MABP drops approximately 4-5 $\mathrm{mm} \mathrm{Hg}$ during the first 7 weeks and then drops another $2 \mathrm{~mm} \mathrm{Hg}$ until weeks 20-21. From then onward, it gradually increases until the end of pregnancy [51].

In hypertensive pregnant women, the initial decrease is smoother $(2 \mathrm{~mm} \mathrm{Hg}$ ) until week 21 , and the subsequent rise is sharper (between 6 and $17 \mathrm{~mm} \mathrm{Hg}$ ) [51].

Despite the variability of MABP during normal or pathological pregnancy (arterial hypertension, preeclampsia), the target CPP between 50 and $60 \mathrm{~mm} \mathrm{Hg}$ should remain unchanged [4-11]. Alterations of autoregulation in preeclampsia/eclampsia can influence CPP targets [12, 15]. To individually optimize the target CPP, multimodal monitoring (ICP, brain tissue oxygen pressure $\left(\mathrm{PbtO}_{2}\right)$, transcranial Doppler, autoregulation test, monitoring of pressure reactivity index), together with continuous fetal monitoring, could provide valuable information.

We must remember than pregnant women are physiologically hemodiluted, so ensuring normal intravascular volume with either isotonic or hypertonic fluids is essential. If the desired MAP is not achieved, vasopressors and/or inotropes should be used according to the individual hemodynamic profile $[1,2,4]$. The target MAP may vary depending on the duration of pregnancy and the ICP; however, it should be adjusted to maintain a CPP between 50 and $60 \mathrm{~mm} \mathrm{Hg}$ [1, 2, 4, 5, 38, 50]. When administering vasopressors, clinicians should carefully consider the potential for inducing placental vasoconstriction. Maternal and fetal blood flow are comparable
[52]. Ten to twelve percent of the total cardiac output corresponds to uterine blood flow $(500-700 \mathrm{~mL} / \mathrm{min})$ [52]. Eighty percent of it is distributed in the placenta and the remaining $20 \%$ in the myometrium [52]. Umbilical flow averages $350-400 \mathrm{~mL} / \mathrm{min}$ [52]. Uterine blood vessels possess smooth muscle, autonomic innervation, and alpha and beta adrenergic receptors [52]. The placental vessels that make up the trophoblast lack smooth muscle and adrenergic receptors, forming a high-flow, lowresistance system that does not respond to endogenous or exogenous adrenergic stimuli [52]. Furthermore, this system does not have autoregulation capacity, and therefore its flow passively follows blood pressure [52].

Rhythmic uterine contractions increase placental flow, whereas hypertonic contractions (labor, oxytocin) decrease it [52]. The vasopressor recommended during pregnancy is phenylephrine (alpha 1 agonist) because it does not modify uterine tone or alter the fetal acid-base state [53]. Data from experimental animals have shown that norepinephrine can cause increased uterine tone, placental hypoperfusion, and fetal bradycardia [54]. According to current definitions and guidelines, antihypertensive therapy is recommended when arterial blood pressure (ABP) levels are $>140 / 90 \mathrm{~mm} \mathrm{Hg}$ [55-58]. Monotherapy is preferred, and first-line oral agents include labetalol, alpha methyldopa, long-acting nifedipine, or another permitted beta blocker (metoprolol, propranolol) [55-58]. Angiotensin-converting enzyme inhibitors and angiotensin receptor blockers should be avoided because of increased risk of fetal renal damage in the second half of pregnancy [55-58]. In cases of severe arterial hypertension, defined by ABP values $>160 / 110 \mathrm{~mm} \mathrm{Hg}$, the first-line agents recommended according to the different scientific organizations are summarized in Table 3 [55-58].

\section{Sedation: Analgesia}

The approach to analgesia/sedation during pregnancy is controversial, and current guidelines do no refer to pregnant patients [59]. There is no evidence that one strategy has shown superiority over others [43, 48]. In general, it is preferable to use short-acting agents to minimize confounding of the neurological examination $[2,48,59$, 60]. During pregnancy, the pain threshold is increased because of high levels of progesterone, which has sedative and analgesic properties through the induction of endorphins and enkephalins and through serotonin release [7, $8,61,62]$. This may allow for lower use of opiates. Yet pain thresholds are variable, so undertreatment of severe pain should be avoided because this could worsen IHT.

Targets of sedation and analgesia should be pain and agitation control, ventilator synchrony, and ICP control without hemodynamic side effects. Protocolization 
Table 3 First-line drugs for management of severe arterial hypertension during pregnancy

\begin{tabular}{|c|c|c|c|c|c|}
\hline Drug & $\begin{array}{l}\text { FDA } \\
\text { cat- } \\
\text { egory }\end{array}$ & Mechanism of action & Dose & Route & Adverse effects \\
\hline Labetalol & C & Alfa and beta blocker & $\begin{array}{l}\text { 10-20 mg. Then } 20-80 \mathrm{mg} \\
\text { every } 20-30 \mathrm{~min}(\max \\
300 \mathrm{mg} \text { ) } \\
\text { Infusion: } 1-2 \mathrm{mg} / \mathrm{min}\end{array}$ & IV & $\begin{array}{l}\text { Materno-fetal bradycardia } \\
\text { Hypotension }\end{array}$ \\
\hline Hydralazine & C & $\begin{array}{l}\text { Peripheral vasodilator } \\
\text { (direct smooth muscle relaxant to inhibition of } \\
\text { inositol trisphosphate-induced } \mathrm{Ca}^{2+} \text { release) }\end{array}$ & $\begin{array}{l}\text { 5-10 mg every } 20-40 \mathrm{~min} \text {. } \\
\text { Infusion: } 0.5-10 \mathrm{mg} / \mathrm{h}\end{array}$ & IV-IM & $\begin{array}{l}\text { Tachycardia } \\
\text { Hypotension } \\
\text { Headache } \\
\text { Flushing } \\
\text { Nausea } \\
\text { ICP increase }\end{array}$ \\
\hline Nifedipine & C & $\mathrm{Ca}^{2+}$ channels blocker & $10-30 \mathrm{mg}$ every $6-8 \mathrm{~h}$ & Oral & $\begin{array}{l}\text { Headaches } \\
\text { Facial flushing } \\
\text { Tachycardia }\end{array}$ \\
\hline Diazoxide & C & $\begin{array}{l}\text { Peripheral vasodilator } \\
\text { (Potassium channel activator) }\end{array}$ & $30-50 \mathrm{mg}$ every $5-15 \mathrm{~min}$ & IV & $\begin{array}{l}\text { Flushing } \\
\text { Hypotension } \\
\text { ICP increase }\end{array}$ \\
\hline Nicardipine & C & $\mathrm{Ca}^{2+}$ channels blocker & $5-15 \mathrm{mg} / \mathrm{h}$ & IV & $\begin{array}{l}\text { Hypotension } \\
\text { Headache } \\
\text { Tachyarrhythmia }\end{array}$ \\
\hline Clevidipine & C & $\mathrm{Ca}^{2+}$ channels blocker & $1-21 \mathrm{mg} / \mathrm{h}$ & IV & $\begin{array}{l}\text { Hypotension } \\
\text { Tachyarrhythmia }\end{array}$ \\
\hline Sodium Nitroprusside & C & Peripheral vasodilator (oxide nitric production) & $0.25-5 \mathrm{ug} / \mathrm{kg} / \mathrm{min}$ & IV & $\begin{array}{l}\text { Hypotension } \\
\text { Cyanide toxicity } \\
\text { ICP increase }\end{array}$ \\
\hline
\end{tabular}

may limit excessive sedation $[48,59,60]$. In deeply sedated patients and in those treated with neuromuscular blocking (NMB) agents, electroencephalography could be a helpful tool. Simplified electroencephalography providing a quantitative bispectral index has shown good correlation with sedation-agitation scales $[48,59$, 63]. The Nociception Coma Scale has recently emerged as a valid tool to assess pain in patients with disorders of consciousness [63].The determination of the adequacy of analgesia for these patients still relies on the observation of indirect signs of pain, for example, tachycardia, systemic hypertension, and ICP elevation during painful interventions $[59,63]$. Available drugs, with their properties, potential uses, and adverse effects in pregnancy, during pregnancy are outlined in Table 4. In general terms, regarding sedation and analgesia for pregnant patients, physicians should always consider the risk of fetal toxicity and respiratory depression. Because there are no specific guidelines regarding sedation and analgesia during pregnancy or during IHT, extrapolation of the evidence obtained from nonpregnant women is recommended $[48,59,60]$. Table 4 details the maternal-fetal risks of commonly used sedatives, analgesics, and neuromuscular blockers (NMB). However, lorazepam is a good choice because it lacks active metabolites and has less residual sedative effect, although its half-life is longer $[48,59,60]$. Propofol has the advantage of its short half-life but must be balanced against the risk of propofol infusion syndrome [48, 59, 60]. Remifentanil and fentanyl can be used safely, even when hemodynamic instability is present $[48,59,60]$. Dexmedetomidine is another good choice because of its pharmacokinetic and pharmacodynamic properties $[48,59,60]$. Fetal risks are similar for all sedative/analgesic drugs, including postpartum respiratory depression and floppy baby syndrome $[48,59,60]$.

NMB is not routinely indicated for ICP control except for specific situations, such as intubation, shivering (hypothermia, controlled normothermia), unconventional ventilatory modes (high airway resistance), ventilator asynchrony, compartment intrabdominal syndrome, or severe acute respiratory distress syndrome. Additionally, NMB can be briefly employed during a dangerous increase of ICP (e.g., secondary to severe and refractory agitation or cough crisis) $[48,64,65]$. NMB precludes neurological examination, masks seizures, and predisposes to infections, deep venous thrombosis, and decubitus ulcers; NMB use is also linked to prolonged mechanical ventilation and may heighten the risk of critical illness myoneuropathy [22, 48, 64, 65].

During pregnancy, short-acting agents that do not cause histamine release (to avoid arterial hypotension or broncoconstriction), such as vecuronium or cisatracurium, are preferred $[48,64,65]$. Cisatracurium is the first 
Table 4 Principal characteristics and concerns of main sedatives, analgesics and paralytic drugs during pregnancy

\begin{tabular}{|c|c|c|c|c|}
\hline Drug & Action mechanism & Half-life & Dose & Considerations in pregnancy \\
\hline Morphine & Analgesia. $\mu$ receptor agonist & $3 \mathrm{~h}$ & $1-10 \mathrm{mg} / \mathrm{h}$ & $\begin{array}{l}\text { Histamine release. Arterial hypotension. Contrain- } \\
\text { dicated in renal dysfunction } \\
\text { Not teratogenic } \\
\text { Neonatal respiratory depression and withdrawal } \\
\text { syndrome }\end{array}$ \\
\hline Fentanyl & Analgesia. $\mu$ receptor agonist & $3 \mathrm{~h}$ & $25-100 \mu g / h$ & $\begin{array}{l}\text { Nonhistamine release and active metabolism. } \\
\text { Consider in renal dysfunction or hemodynamic } \\
\text { instability } \\
\text { Not teratogenic } \\
\text { Neonatal respiratory depression and withdrawal } \\
\text { syndrome }\end{array}$ \\
\hline Remifentanil & Analgesia $\mu$ receptor agonist & $3 \mathrm{~min}$ & $0.5-2 \mu \mathrm{g} / \mathrm{kg} / \mathrm{min}$ & $\begin{array}{l}\text { Metabolism by serum esterases } \\
\text { Not teratogenic }\end{array}$ \\
\hline Midazolam & $\begin{array}{l}\text { GABA agonist. Sedative, anxiolysis, hypnotic, } \\
\text { amnesic, antiepileptic }\end{array}$ & $3-11 \mathrm{~h}$ & $1-10 \mathrm{mg} / \mathrm{h}$ & $\begin{array}{l}\text { Active metabolites. Development of tolerance. } \\
\text { Less safe if renal dysfunction } \\
\text { Prolonged sedation after discontinuation } \\
\text { Arterial hypotension. Unclear if teratogenic effect } \\
\text { Neonatal } \\
\text { respiratory depression and floppy baby } \\
\text { syndrome }\end{array}$ \\
\hline Lorazepam & $\begin{array}{l}\text { GABA agonist. Sedative, anxiolysis, hypnotic, } \\
\text { amnesic, antiepileptic }\end{array}$ & $8-15 \mathrm{~h}$ & $1-10 \mathrm{mg} / \mathrm{h}$ & $\begin{array}{l}\text { No active metabolites. Less residual sedation. } \\
\text { Unclear if teratogenic effect } \\
\text { Neonatal } \\
\text { respiratory depression and floppy baby } \\
\text { syndrome }\end{array}$ \\
\hline Propofol & $\begin{array}{l}\text { GABA, glycine, muscarinic, and nicotinic recep- } \\
\text { tors agonist. Sedative/anxiolytic, } \\
\text { amnestic, and anticonvulsant }\end{array}$ & $30 \mathrm{~min}$ & 5 to $50 \mathrm{mg} / \mathrm{kg} / \mathrm{min}$ & $\begin{array}{l}\text { High hepatic and extrahepatic metabolism } \\
\text { Decreases systemic vascular resistance and can } \\
\text { provoke myocardial depression } \\
\text { May be employed during acute renal or liver } \\
\text { dysfunction. Propofol infusion syndrome (high } \\
\text { and prolonged doses) } \\
\text { Not teratogenic }\end{array}$ \\
\hline Dexmedetomidine & $\begin{array}{l}\text { Selective presynaptic a2 agonist. Sedative, } \\
\text { analgesic }\end{array}$ & $2-3 \mathrm{~h}$ & $0.2-1.5 \mathrm{mg} / \mathrm{kg} / \mathrm{h}$ & $\begin{array}{l}\text { No respiratory depression } \\
\text { Decreases catecholamines. Bradycardia and arte- } \\
\text { rial hypotension (bolus) }\end{array}$ \\
\hline Ketamine & $\begin{array}{l}\text { NMDA receptor antagonist. Analgesic, hyp- } \\
\text { notic, anesthetic and sympathomimetic }\end{array}$ & $1.5-3 \mathrm{~h}$ & $1-5 \mathrm{mg} / \mathrm{kg} / \mathrm{h}$ & $\begin{array}{l}\text { Not teratogenic } \\
\text { Uterine contractions (dose-dependent). Neonatal } \\
\quad \text { respiratory depression } \\
\text { Not a first choice during pregnancy }\end{array}$ \\
\hline Vecuronium & No depolarizing neuromuscular blocker & $0.5-2 \mathrm{~h}$ & $1-2 \mathrm{mg} / \mathrm{kg} / \mathrm{min}$ & $\begin{array}{l}\text { Contraindicated in renal or liver failure } \\
\text { No problems for fetus }\end{array}$ \\
\hline Cisatracurium & No depolarizing neuromuscular blocker & $25 \mathrm{~min}$ & $2-4 \mathrm{mg} / \mathrm{kg} / \mathrm{min}$ & No problems during pregnancy \\
\hline
\end{tabular}

choice in the presence of acute liver or kidney injury [48, $64,65]$.

Both drugs may be used safely during pregnancy if indicated. Both cross the placenta in small amounts but do not lead to adverse neonatal outcomes or neonatal paralysis [48] (Table 3).

\section{Surgery and CSF Drainage}

Evacuation of mass lesions (such as epidural, subdural, or intracerebral hematomas) when indicated and CSF drainage in cases of acute hydrocephalus (such as with poor-grade subarachnoid hemorrhage) are effective strategies for ICP control and should be promptly considered when pertinent [66, 67]. Decompressive craniectomy is also a powerful measure to ameliorate IHT, performed either unilaterally in patients with advanced tissue shift from space-occupying lesions or bilaterally in cases of severe cerebral edema [68]. Although there are no largescale studies that support this recommendation, craniectomy can be a salvage tool during pregnancy, especially in low-income regions or where neuromonitoring is not available [68]. Additionally, it can help maintain and ensure fetal viability when the damage to the mother is devastating and irreversible [69]. Surgery and anesthesia are not without risk for both the mother and the fetus. During the first trimester, the risk of fetal loss and severe 
congenital malformations should be discussed, considering in certain cases the possibility of interrupting the pregnancy, whereas during the second and third trimesters, surgical procedures can be performed with a good margin of safety [26]. Beyond week 34, it is generally advisable to proceed with cesarean delivery at the time of the neurosurgery [26].

CSF drainage is an effective and transitory measure to lower ICP, especially in the presence of acute hydrocephalus $[2,27,67]$. The indications for ventriculostomy are not affected by pregnancy. Instead, controlled lumbar drainage is a less desirable option during pregnancy because of the compression of the thecal space [20].

\section{Osmotherapy}

Mannitol and hypertonic saline solution (HSS) share similar distribution in the extracellular space, but mannitol crosses the placental barrier and is excreted in fetal urine $[27,70]$. Animal studies have shown that mannitol increases maternal osmolality and may cause fetal dehydration, hypovolemia, hypoxia, bradycardia, and changes in acid-base status [70]. It is unclear if this phenomenon is dose dependent $[4,70]$. The safety of intravenous hypertonic saline in pregnancy is not well established. In the past, intrauterine instillation of hypertonic saline was used to induce abortions in the midtrimester [71]; however, this experience is most likely irrelevant for the evaluation of the risks related to intravenous administration. There are no human studies assessing mannitol or HSS during pregnancy. Low doses of mannitol $(0.25-0.5 \mathrm{~g} / \mathrm{kg})$ are generally considered safe [72]. Yet HSS may be more physiological, and we therefore favor the use of HSS when central venous access is available and the patient does not have signs of heart failure.

There are no safety data on the use of hypertonic lactate in pregnancy.

\section{Hyperventilation}

Physiologically, pregnant women maintain $\mathrm{PaCO}_{2}$ levels between 30 and $32 \mathrm{~mm} \mathrm{Hg}$. Therefore, the $\mathrm{PaCO}_{2}$ goal when hyperventilating a pregnant patient should probably be between 26 and $28 \mathrm{~mm} \mathrm{Hg}[4,7,8]$. There are no studies on hyperventilation during pregnancy; however, despite the physiological and adaptive decrease in $\mathrm{CO}_{2}$ levels and the alkalinity of CSF during pregnancy, vascular reactivity to $\mathrm{CO}_{2}$ remains unchanged or can even be increased $[73,74]$.

Hyperventilation should be considered after safer measures have failed to bring the ICP under control, and it should only be induced under strict fetal monitoring.

To our knowledge, there are no studies evaluating fetal complications from maternal hyperventilation; however, hypocapnia produces systemic vasoconstriction (myocardial, renal, splanchnic), and the uteroplacental circulation does not escape this effect [4, 75, 76]. Hence, acceptable indications for hyperventilation should be restricted to brain herniation, potentially lethal increases in ICP (Lundberg A waves), or IHT secondary to increased CBF (hyperemia). Hyperventilation should ideally be used as briefly as possible, but if used for more than a few minutes, it should not be stopped suddenly to avoid rebound increases in ICP $[75,76]$.

\section{Refractory IHT: Second-line Therapies}

When there is no response to the aforementioned therapies, IHT is defined as refractory [2, 27]. In this situation, available therapies are scarce, and they are associated with severe complications. None of the second-tier options have been formally evaluated during pregnancy.

The use of barbiturates at high doses is not a safe option because of its strongly negative impact on hemodynamics and its profound maternal immunosuppressive effects [2]. Barbiturates cross the placenta and distribute widely in the fetus [77]. During the first trimester of pregnancy, they can cause malformations (spinal cord) [77]. Additionally, their administration is associated with fetal hemorrhages, likely related to vitamin $\mathrm{K}$ deficiency [77]. Neonatal abstinence syndrome may also occur after delivery when barbiturates are prescribed during the third trimester of pregnancy [77].

Indomethacin is a nonsteroidal antiinflammatory agent that causes cerebral vasoconstriction and has been used as a rescue measure (not included in current protocols) for the control of refractory IHT [2]. It has tocolytic capacity by reducing the number and frequency of uterine contractions [78]. It should not be used beyond 32 weeks' gestation and produces a decrease in fetal diuresis and oligohydramnios [78]. Additionally, it can cause jaundice, premature closure of the arteriovenous ductus, necrotizing enterocolitis, intraventricular hemorrhage, and leukomalacia in the fetus [78].

Therapeutic hypothermia has anecdotally been reported during pregnancy in the context of cardiac arrest but not for control of IHT [79]. Hypothermia can induce fetal bradycardia; therefore, strict monitoring of the fetal heart rate (FHR) is mandatory. There are case reports of induced hypothermia $\left(33-35{ }^{\circ} \mathrm{C}\right)$ between 13 and 20 weeks' gestation resulting in favorable maternal functional and good fetal outcomes [79].

As previously mentioned, decompressive craniectomy is a valid option to treat refractory IHT [68]. Data from randomized controlled trials are very supportive of the benefit of decompressive hemicraniectomy for young patients with hemispheric stroke [80] but do not show clear benefits in functional outcome after severe 
traumatic brain injury $[81,82]$. There have been no trials of surgical decompression for other causes of refractory IHT. Thus, decompressive craniectomy should be used very selectively and after careful evaluation of individual circumstances (prognosis of the cause of the IHT, fetal viability, etc.).

In fact, given the safety concerns with other rescue treatments, craniectomy should be particularly considered as a preferable alternative in pregnant patients with refractory IHT.

\section{Maternal-fetal Monitoring}

Apart from classic systemic maternal monitoring (electrocardiography, $\mathrm{SaO}_{2}$, capnography, arterial pressure, etc.), serial fetal monitoring by using conventional or Doppler ultrasonography is essential [26, 83, 84]. Fetal monitoring should be considered in all pregnant patients with IHT and may include FHR and obstetrical ultrasound parameters, such as fetal physical characteristics, weight and position, placental localization and blood flow, umbilical flow, and amniotic fluid volume [26, 83 , 84].

The analysis of the variability of the FHR is a crucial parameter because its alteration denotes severe fetal distress [26, 83, 84]. The normal FHR ranges from 110 to 160 beats per minute [85]. Periodic acceleration phenomena associated with fetal movements (more than 15 beats of $15 \mathrm{~s}$ duration) and FHR variability (spontaneous changes between 6 and 25 beats per minute according to fetal cardiac demands) are physiological [85]. Decelerations and absence of variability denote severe fetal distress [85].

\section{Fetal and Maternal Considerations About Delivery}

Maternal homeostasis is vital to fetal well-being. The prioritization of fetal health over maternal health can lead to unnecessary delays in maternal care and suboptimal treatment of life-threatening conditions, such as IHT, resulting in poor outcomes for both mother and fetus.

The survival of the fetus depends on uterine perfusion and oxygen delivery $[7,8,86]$. The uteroplacental circulation has no autoregulatory properties; thus, blood flow passively depends on maternal MAP, and peripheral vasoconstriction can compromise uterine perfusion [7, $8,52,86]$. The fetus is usually considered viable when it has a $50 \%$ chance of extrauterine survival $[86,87]$. If neonatal facilities are available, this usually means at least 25-26 weeks' gestation or an estimated weight of $750 \mathrm{~g}$ $[86,87]$. By using cutoffs of 24 weeks' gestation and an estimated weight of 500-600 g, the chances of survival are reduced to $20-30 \%[86,87]$. Decisions on fetal viability are based on the best estimation of gestational age. When estimating the fetal age in the emergency room or intensive care unit, if the fundus of the uterus extends beyond the umbilicus, the fetus is potentially viable [86, 87]. When emergency neurosurgery is indicated and the fetus is viable, cesarean delivery should be performed under general anesthesia either immediately before or along with the neurosurgical intervention $[4,26,72,88$, 89].

The decision whether to interrupt a pregnancy depends on the severity of the mother's clinical situation and the age and clinical condition of the fetus, and it should always be reached by consensus from a multidisciplinary team [72, 86-89]. A shared decision-making approach is recommended and should include the patient (if possible) and family.

In cases of preterm labor or early uterine contractions during pregnancy, tocolytics (oxytocin receptor antagonist, beta adrenergic agonists, or calcium channel blockers) can be used, but the safety of them is unknown. Oxytocin and its synthetic analogues can be used with a good safety margin; however, the lowest possible dose should be employed at a slow infusion rate because they can potentially cause vasodilation, arterial hypotension, and increased ICP $[90,91]$.

\section{Maternal Brain Death}

Intractable IHT may result in maternal brain death. In some of these instances, fetal viability is preserved and the life of the developing fetus still depends on somatic functions of the deceased mother [92]. In some cases, interventions on the mother's body are justified to preserve the life of the fetus [92]. This point is extremely controversial and complex because of the bioethical dilemmas specifically related to pregnancy [93]. Decision-makers must consider the maternal-fetal unit, and all aspects of care must be discussed in a multidisciplinary manner, with inclusion of medical, ethical, and legal experts [93]. Regarding the care of a pregnant woman who has suffered a catastrophic and irreversible brain injury, decision-makers should consider the following factors: (1) prognosis of the injury, gestational age and its impact, and of the therapeutic interventions on the fetus; (2) the mother's wishes; (3) commitment to decisionmaking by the mother's close relatives or surrogates; and (4) current local laws [93].

A systematic review that included 30 cases of braindead pregnant mothers found that the mean gestational age at the time of brain death was 22 weeks and at the time of delivery was 29.5 weeks; 12 children survived and developed normally over the subsequent 2 years [94]. Fetus survival depended on several factors, including the mother's gestational age and complications such as diabetes insipidus, hemodynamic instability, hypopituitarism, hypothermia, metabolic instability, and neonatal acute distress respiratory syndrome $[92,94]$. 


\section{Outcome}

There are no studies specifically addressing the maternal and fetal outcomes related to IHT during pregnancy. Yet $60 \%$ of deaths in the peripartum period are due to hypertensive disorders (preeclampsia/eclampsia) and venous thromboembolism [4]. Preeclampsia, eclampsia, and hemolysis, elevated liver enzymes, and low platelet count (HELLP) syndrome are associated with $1.5 \%$ mortality in developed countries, but in developing countries, the mortality rate may range between 10 and $33 \%$ [95]. Traumatic brain injury is the cause responsible for maternal death in $10 \%$ of cases [96]. Poor functional outcome (modified Rankin score of 3 or more) has been reported after $16 \%$ of ischemic strokes and nearly $40 \%$ of hemorrhagic strokes. The mortality rate during the peripartum period is $2.7 \%$ and $11.7 \%$ for ischemic and hemorrhagic stroke, respectively [97-99].

\section{Conclusions}

IHT is a rare complication during pregnancy, and its management remains empirical and extrapolated from data on nonpregnant patients. However, this special situation demands attention to special considerations, including physiological changes related to the pregnancy (e.g., expansion of circulating volume, hypocapnia, raised intraabdominal pressure), pharmacokinetic changes affecting multiple classes of medications, and the risks to the developing fetus. ICP management protocols should therefore be adjusted accordingly to optimize maternal and fetal outcomes. The numerous gaps in knowledge identified in this review highlight the need for more research on this infrequent but important clinical situation.

\footnotetext{
Author details

${ }^{1}$ Neurointensive Care Unit, Sanatorio Pasteur, Catamarca, Argentina.

${ }^{2}$ Intensive Care, Hospital Carlos Malbran, Catamarca, Argentina. ${ }^{3}$ Anesthesia and Intensive Care, San Martino Policlinico Hospital, Investigational Research for Critical Care for Oncology and Neurosciences, Genoa, Italy. ${ }^{4}$ Division of Neurological Surgery, University of Sao Paulo Medical School, Sao Paulo, Brazil. ${ }^{5}$ Neuroscience Intensive Care Unit, Mayo Clinic, Rochester, MN, USA.
}

\section{Author contributions}

DAG: Search and analysis of the literature; design and writing of the original manuscript and later versions; reply to reviewers. CR and WSP: Revision and first edition of the manuscript. AAR: Analysis, global content review; grammar adaptation and correction; final editing of the manuscript and of the response to the reviewers. The final manuscript was approved by all authors.

\section{Source of support}

None.

\section{Conflicts of interest}

The authors have nothing to disclose.

\section{Ethical approval/informed consent}

All procedures performed in studies involving human participants were in accordance with the ethical standards of the institutional and/or national research committee and with the 1964 Helsinki declaration and its later amendments or comparable ethical standards.

\section{Publisher's Note}

Springer Nature remains neutral with regard to jurisdictional claims in published maps and institutional affiliations.

Received: 30 March 2021 Accepted: 12 August 2021

Published online: 7 September 2021

\section{References}

1. Stochetti N, Maas AIR. Traumatic intracranial hypertension. N Eng J Med. 2014:370:2121-30.

2. Godoy DA, Videtta W, Di Napoli M. Practical approach to posttraumatic intracranial hypertension according to pathophysiologic reasoning. Neurol Clin. 2017:35:613-40.

3. Wilson MH. Monro-Kellie 2.0: the dynamic vascular and venous pathophysiological components of intracranial pressure. J Cereb Blood Flow Metab. 2016;36:1338-50.

4. Frontera JA, Ahmed W. Neurocritical care complications of pregnancy and puerperum. J Crit Care. 2014;29(6):1069-81.

5. Burn MS, Sheth SS, Sheth KN. Neurocritical care of the pregnant patient. Handb Clin Neurol. 2020;171:205-13.

6. Ladhani NNN, Swartz RH, Foley N, Nerenberg K, Smith EE, Gubitz G, et al. Canadian stroke best practice consensus statement: acute stroke management during pregnancy. Int J Stroke. 2018;13:743-58.

7. Cunningham F, Leveno K, Bloom S, Hauth J, Gilstrap L, Wenstrom K. Maternal physiology. In: Obstetrics W, editor. 22nd edition. New York: McGraw Hill; 2005. p. 121-50.

8. Datta S, Kodali B, Segal S. Maternal physiological changes during pregnancy. Labor Postpartum Period. 2010. https://doi.org/10.1007/ 978-0-387-88602-2_1

9. Johnson AC, Cipolla MJ. The cerebral circulation during pregnancy: adapting to preserve normalcy. Physiology (Bethesda). 2015;30(2):139-47.

10. Cipolla MJ. The adaptation of the cerebral circulation to pregnancy: mechanisms and consequences. J Cereb Blood Flow Metab. 2013;33(4):465-78.

11. Cipolla MJ, Bishop N, Chan SL. Effect of pregnancy on autoregulation of cerebral blood flow in anterior versus posterior cerebrum. Hypertension. 2012;60:705-11.

12. Janzarik WG, Ehlers E, Ehmann R, Gerds TA, Schork J, Mayer S, Gabriel B, Weiller C, Prömpeler H, Reinhard M. Dynamic cerebral autoregulation in pregnancy and the risk of preeclampsia. Hypertension. 2014;63:161-6.

13. Janzarik WG, Jacob J, Katagis E, Markfeld-Erol F, Sommerlade L, Wuttke M, Reinhard M. Preeclampsia postpartum: Impairment of cerebral autoregulation and reversible cerebral hyperperfusion. Pregnancy Hypertens. 2019;17:121-6.

14. Cipolla MJ, Sweet JG, Chan SL. Cerebral vascular adaptation to pregnancy and its role in the neurological complications of eclampsia. J Appl Physiol. 2011;110(2):329-39.

15. Jones-Muhammad M, Warrington JP. Cerebral blood flow regulation in pregnancy, hypertension, and hypertensive disorders of pregnancy. Brain Sci. 2019;9:224.

16. Carmeliet P, Moons L, Luttun A, Vincenti V, Compernolle V, De Mol M, Wu Y, Bono F, Devy L, Beck H, Scholz D, Acker T, DiPalma T, Dewerchin M, Noel A, Stalmans I, Barra A, Blacher S, VandenDriessche T, Ponten A, Eriksson U, Plate KH, Foidart JM, Schaper W, Charnock-Jones DS, Hicklin DJ, Herbert JM, Collen D, Persico MG. Synergism between vascular endothelial growth factor and placental growth factor contributes to angiogenesis and plasma extravasation in pathological conditions. Nat Med. 2001;7:575-83.

17. Wallace K, Bean C, Bowles T, Spencer SK, Randle W, Kyle PB, Shaffery J. Hypertension, anxiety, and blood-brain barrier permeability are increased in postpartum severe preeclampsia/hemolysis, elevated liver enzymes, and low platelet count syndrome rats. Hypertension. 2018;72:946-54.

18. Burwick RM, Togioka BM, Speranza RJ, Gaffney JE, Roberts VHJ, Frias AE, Rincón M. Assessment of blood-brain barrier integrity and neuroinflammation in preeclampsia. Am J Obstet Gynecol. 2019;221(269):e1-269.e8. 
19. Quick AM, Cipolla MJ. Pregnancy-induced up-regulation of aquaporin-4 protein in brain and its role in eclampsia. FASEB J. 2005;19:170-5.

20. Takiguchi T, Yamaguchi S, Tezuka M, Furukawa N, Kitajima T. Compression of the subarachnoid space by the engorged epidural venous plexus in pregnant women. Anesthesiology. 2006;105:848-51.

21. Hirabayashi Y, Shimizu R, Saitoh K, Fukuda H, Igarashi T. Acid-base state of cerebrospinal fluid during pregnancy and its effect on spread of spinal anaesthesia. Br J Anaesthesia. 1996;77:352-5.

22. Altemus M, Fong J, Yang R, Damast S, Luine V, Ferguson D. Changes in cerebrospinal fluid neurochemistry during pregnancy. Biol Psychiatry. 2004;56:386-92.

23. Lee LK. Physiological adaptations of pregnancy affecting the nervous system. Semin Neurol. 2007;27:405-10.

24. Ansari J, Carvalho B, Shafer SL, Flood P. Pharmacokinetics and pharmacodynamics of drugs commonly used in pregnancy and parturition. Anesth Analg. 2016;122:786-804.

25. Pariente G, Leibson T, Carls A, Adams-Webber T, Ito S, Koren G. Pregnancyassociated changes in pharmacokinetics: a systematic review. PLoS Med. 2016;13:e1002160.

26. Chowdhury T, Chowdhury M, Schaller B, Cappellani RB, Daya J. Perioperative considerations for neurosurgical procedures in the gravid patient: continuing professional development. Can J Anaesth. 2013;60(11):1139-55.

27. Carney N, Totten AM, O'Reilly C, Ullman JS, Hawryluk GW, Bell MJ, et al. Guidelines for the management of severe traumatic brain injury. Neurosurgery. 2017;80:6-15.

28. Vik A, Nag T, Fredriksli OA, Skandsen T, Moen KG, Schirmen Mikalsen K, et al. Relationship of "dose" of intracranial hypertension to outcome in severe traumatic brain injury. J Neurosurg. 2008;109:678-84.

29. Jha RM, Elmer J, Zusman BE, Desai S, Puccio AM, Okonkwo DO, et al. Intracranial pressure trajectories: a novel approach to informing severe traumatic brain injury phenotypes. Crit Care Med. 2018;46:1792-802.

30. Chesnut RM, Gautille T, Blunt BA, et al. The localizing value of asymmetry in pupil size in severe head injury: relation to lesion type and location. Neurosurgery. 1994;34:840-6.

31. Chen MM, Coakley FV, Kaimal A, Laros RK Jr. Guidelines for computed tomography and magnetic resonance imaging use during pregnancy and lactation. Obstet Gynecol. 2008;112:333-40.

32. Committee Opinion No. 723 : Guidelines for diagnostic imaging during pregnancy and lactation. Obstet Gynecol. 2017; 130: e210-e216. Erratum in: Obstet Gynecol. 2018; 132: 786.

33. Marshall LF, Marshall SB, Klauber MR, van Berkum CM. A new classification of head injury based on computerized tomography. J Neurosurg. 1991;75(Suppl):S14-20.

34. Alali AS, Temkin N, Barber J, Pridgeon J, Chaddock K, Dikmen S, Hendrickson P, Videtta W, Lujan S, Petroni G, Guadagnoli N, Urbina Z, Chesnut RM. A clinical decision rule to predict intracranial hypertension in severe traumatic brain injury. J Neurosurg. 2018;8:1-8.

35. Fernando SM, Tran A, Cheng W, Rochwerg B, Taljaard M, Kyeremanteng K, English SW, Sekhon MS, Griesdale DEG, Dowlatshahi D, McCredie VA, Wijdicks EFM, Almenawer SA, Inaba K, Rajajee V, Perry JJ. Diagnosis of elevated intracranial pressure in critically ill adults: systematic review and meta-analysis. BMJ. 2019;366:14225.

36. Meyer MJ, et al. Acute management of acquired brain injury part I: an evidence-based review of non-pharmacological interventions. Brain Inj. 2010;24:694-705.

37. Meyer MJ, et al. Acute management of acquired brain injury part II: an evidence-based review of pharmacological interventions. Brain Inj. 2010;24:706-21.

38. Hawryluk GWJ, Aguilera S, Buki A, Bulger E, Citerio G, Cooper DJ, Arrastia RD, Diringer M, Figaji A, Gao G, Geocadin R, Ghajar J, Harris O, Hoffer A, Hutchinson P, Joseph M, Kitagawa R, Manley G, Mayer S, Menon DK, Meyfroidt G, Michael DB, Oddo M, Okonkwo D, Patel M, Robertson C, Rosenfeld JV, Rubiano AM, Sahuquillo J, Servadei F, Shutter L, Stein D, Stocchetti N, Taccone FS, Timmons S, Tsai E, Ullman JS, Vespa P, Videtta W, Wright DW, Zammit C, Chesnut RM. A management algorithm for patients with intracranial pressure monitoring: the Seattle international severe traumatic brain injury consensus conference (SIBICC). Intensive Care Med. 2019;45:1783-94.

39. Godoy DA, Videtta W, Santa Cruz R, Silva X, Aguilera-Rodríguez S, CarreñoRodríguez JN, Ciccioli F, Piñero G, Ciro JD, da Re-Gutiérrez S, Domeniconi
G, Fischer D, Hernández O, Lacerda-Gallardo A, Mejía J, Panhke P, Romero C, Lora FS, Soler-Morejón C, Sufan JL, Montes JM, Fuenzalida LC, Parahnos JL, Jibaja M. En representación del Consorcio Latinoamericano de Injuria Cerebral (LABIC). General care in the management of severe traumatic brain injury: Latin American consensus. Med Intensiva. 2020;44(8):500-8.

40. Godoy DA, Di Napoli M, Rabinstein AA. Treating hyperglycemia in neurocritical patients: benefits and perils. Neurocrit Care. 2010;13:425-38.

41. Vespa P, Boonyaputthikul R, McArthur D, Miller C, et al. Intensive insulin therapy reduces microdialysis glucose values without altering glucose utilization or improving the lactate/pyruvate ratio after traumatic brain injury. Crit Care Med. 2006;34:850-6.

42. Kinsella SM, Winton AL, Mushambi MC, Ramaswamy K, Swales H, Quinn AC, Popat M. Failed tracheal intubation during obstetric general anaesthesia: a literature review. Int J Obstet Anesth. 2015;24:356-74.

43. Mushambi MC, Kinsella SM, Popat M, Swales H, Ramaswamy KK, Winton AL, Quinn AC; Obstetric Anaesthetists' Association; Difficult Airway Society. Obstetric Anaesthetists' Association and Difficult Airway Society guidelines for the management of difficult and failed tracheal intubation in obstetrics. Anaesthesia. 2015; 70:1286-1306.

44. Itskovitz J, LaGamma EF, Rudolph AM. The effect of reducing umbilical blood flow on fetal oxygenation. Am J Obstet Gynecol. 1983;145:813-8.

45. Dilts PV Jr, Brinkman CR 3rd, Kirschbaum TH, Assali NS. Uterine and systemic hemodynamic interrelationships and their response to hypoxia. Am J Obstet Gynecol. 1969;103:138-57.

46. Walker AM, Oakes GK, Ehrenkranz R, McLaughlin M, Chez RA. Effects of hypercapnia on uterine and umbilical circulations in conscious pregnant sheep. J Appl Physiol. 1976;41:727-33.

47. Haring OM. Cardiac malformations in rats induced by exposure of the mother to carbon dioxide during pregnancy. Circ Res. 1960;8:1218-27.

48. Pacheco LD, Saade GR, Hankins GD. Mechanical ventilation during pregnancy: sedation, analgesia, and paralysis. Clin Obstet Gynecol. 2014;57(4):844-50.

49. Schwaiberger D, Karcz M, Menk M, Papadakos PJ, Dantoni SE. Respiratory failure and mechanical ventilation in the pregnant patient. Crit Care Clin. 2016:32(1):85-95.

50. Munnur U, Bandi V, Guntupalli KK. Management principles of the critically ill obstetric patient. Clin Chest Med. 2011;32:53-60.

51. Ayala DE, Hermida RC, Mojón A, Fernández JR, Silva I, Ucieda R, Iglesias M. Blood pressure variability during gestation in healthy and complicated pregnancies. Hypertension. 1997;30:611-8.

52. Nag DS, Samaddar DP, Chatterjee A, Kumar H, Dembla A. Vasopressors in obstetric anesthesia: a current perspective. World J Clin Cases. 2015;3:58-64

53. Lee A, Ngan Kee WD, Gin T. A quantitative, systematic review of randomized controlled trials of ephedrine versus phenylephrine for the management of hypotension during spinal anesthesia for cesarean delivery. Anesth Analg. 2002;94:920-6.

54. Stevens $A D$, Lumbers ER. Effects of intravenous infusions of noradrenaline into the pregnant ewe on uterine blood flow, fetal renal function, and lung liquid flow. Can J Physiol Pharmacol. 1995;73(2):202-8.

55. Butalia S, Audibert F, Côté AM, Firoz T, Logan AG, Magee LA, et al. Hypertension Canada's 2018 guidelines for the management of hypertension in pregnancy. Can J Cardiol. 2018:34:526-31.

56. Podymow T, August P. Update on the use of antihypertensive drugs in pregnancy. Hypertension. 2008;51:960-9.

57. Nij Bijvank SW, Duvekot JJ. Nicardipine for the treatment of severe hypertension in pregnancy: a review of the literature. Obstet Gynecol Surv. 2010;65:341-7.

58. Finger JR, Kurczewski LM, Brophy GM. Clevidipine versus nicardipine for acute blood pressure reduction in a neuroscience intensive care population. Neurocrit Care. 2017;26:167-73.

59. Devlin JW, Skrobik Y, Gélinas C, et al. Clinical practice guidelines for the prevention and management of pain, agitation/sedation, delirium, immobility, and sleep disruption in adult patients in the ICU. Crit Care Med. 2018;46(9):e825-73.

60. Neuman G, Koren G. Safety of procedural sedation in pregnancy. J Obstet Gynaecol Can. 2013;35(2):168-73.

61. Gintzler AR. Endorphin-mediated increases in pain threshold during pregnancy. Science. 1980;210:193-5.

62. Jayaram A, Carp H. Progesterone-mediated potentiation of spinal sufentanil in rats. Anesth Analg. 1993;76:745-50. 
63. Le Roux P, Menon DK, Citerio G, et al. Consensus summary statement of the international multidisciplinary consensus conference on multimodality monitoring in neurocritical care: a statement for healthcare professionals from the neurocritical care society and the European Society of Intensive. Intensive Care Med. 2014;40:1189-209.

64. Sanfilippo F, Santonocito C, Veenith T, Astuto M, Maybauer MO. The role of neuromuscular blockade in patients with traumatic brain injury: a systematic review. Neurocrit Care. 2015;22:325-34.

65. Renew JR, Ratzlaff R, Hernandez-Torres V, et al. Neuromuscular blockade management in the critically III patient. J Intensive Care. 2020;8:37.

66. Bullock RM, Chesnut R, Ghajar J, Gordon D, Hartl R, Newell DW, Servadei F, Walters BC, Wilberger JE. Guidelines for the surgical management of traumatic brain injury author group. Neurosurgery. 2006;58(3):S2-vi.

67. Rabinstein AA, Lanzino G, Wijdicks EF. Multidisciplinary management and emerging therapeutic strategies in aneurysmal subarachnoid haemorrhage. Lancet Neurol. 2010;9(5):504-19.

68. Hawryluk GW, Rubiano AM, Totten AM, O'Reilly C, Ullman JS, Bratton SL, Ghajar J. Guidelines for the management of severe traumatic brain injury: 2020 update of the decompressive craniectomy recommendations. Neurosurgery. 2020;87(3):427-34.

69. Whitney N, Raslan AM, Ragel BT. Decompressive craniectomy in a neurologically devastated pregnant woman to maintain fetal viability. J Neurosurg. 2012;116(3):487-90.

70. Basso A, Fernandez A, Althabe O, Sabini G, Piriz H, Belitzky R. Passage of mannitol from mother to amniotic fluid and fetus. Obstet Gynecol. 1977:49:628-31.

71. Hern WM. Midtrimester abortion Obstet Gynecol Annu. 1981;10:375-422

72. Reitman E, Flood P. Anaesthetic considerations for nonobstetric surgery during pregnancy. Br J Anaesth. 2011;107(suppl 1):i72-8.

73. Riskin-Mashiah S, Belfort MA, Saade GR, Herd JA. Cerebrovascular reactivity in normal pregnancy and preeclampsia. Obstet Gynecol. 2001;98:827-32

74. Steinback CD, King EC, Davenport MH. Longitudinal cerebrovascular reactivity during pregnancy: a case study. Appl Physiol Nutr Metab. 2015;40(6):636-9.

75. Godoy DA, Seifi A, Garza D, Lubillo-Montenegro S, Murillo-Cabezas F. Hyperventilation therapy for control of posttraumatic intracranial hypertension. Front Neurol. 2017:8:250.

76. Godoy DA, Rovegno M, Lazaridis C, Badenes R. The effects of arterial $\mathrm{CO}_{2}$ on the injured brain: two faces of the same coin. J Crit Care. 2020;61:207-15.

77. Nobay F, Acquisto NM. Barbiturates. In: Wexler P, editor. Encyclopedia of toxicology. 3rd ed. Cambridge: Academic Press; 2014. p. 363-7.

78. Abou-Ghannam G, Usta IM, Nassar AH. Indomethacin in pregnancy: applications and safety. Am J Perinatol. 2012;29(3):175-86.

79. Oguayo KN, Oyetayo OO, Stewart D, Costa SM, Jones RO. Successful use of therapeutic hypothermia in a pregnant patient. Tex Heart Inst J. 2015;42(4):367-71.

80. Hofmeijer J, Kappelle LJ, Algra A, Amelink GJ, van Gijn J, van der Worp $H B$; HAMLET investigators. Surgical decompression for space-occupying cerebral infarction (the hemicraniectomy after middle cerebral artery infarction with life-threatening edema trial [HAMLET]): a multicentre, open, randomised trial. Lancet Neurol. 2009; 8: 326-33.

81. Cooper DJ, Rosenfeld JV, Murray L, Arabi YM, Davies AR, D'Urso P, Kossmann T, Ponsford J, Seppelt I, Reilly P, Wolfe R; DECRA Trial Investigators; Australian and New Zealand Intensive Care Society Clinical Trials Group. Decompressive craniectomy in diffuse traumatic brain injury. N Engl J Med. 2011; 364: 1493-502. Erratum in: N Engl J Med. 2011; 365: 2040.
82. Hutchinson PJ, Kolias AG, Timofeev IS, Corteen EA, Czosnyka M, Timothy J, Anderson I, Bulters DO, Belli A, Eynon CA, Wadley J, Mendelow AD, Mitchell PM, Wilson MH, Critchley G, Sahuquillo J, Unterberg A, Servadei F, Teasdale GM, Pickard JD, Menon DK, Murray GD, Kirkpatrick PJ; RESCUEicp Trial Collaborators. Trial of decompressive craniectomy for traumatic intracranial hypertension. N Engl J Med. 2016; 375: 1119-30.

83. Tuncali B, Aksun M, Katircioglu K, Akkol I, Savaci S. Intraoperative fetal heart rate monitoring during emergency neurosurgery in a parturient. J Anesth. 2006:20:40-3.

84. Kilpatrick CC, Puig C, Chohan L, Monga M, Orejuela FJ. Intraoperative fetal heart rate monitoring during non-obstetric surgery in pregnancy: a practice survey. South Med J. 2010;103:212-5.

85. Ayres-de-Campos D, Arulkumaran S. FIGO intrapartum fetal monitoring expert consensus panel. FIGO consensus guidelines on intrapartum fetal monitoring. Int J Gynaecol Obstet. 2015;131(1):3-29.

86. Desjardins G. Management of the injured pregnant patient. Trauma Org. Trauma in Pregnancy. 2008.

87. Jain V, Chari R, Maslovitz S, Farine D; Maternal Fetal Medicine Committee, Bujold E, Gagnon R, Basso M, Bos H, Brown R, Cooper S, Gouin K, McLeod NL, Menticoglou S, Mundle W, Pylypjuk C, Roggensack A, Sanderson F. Guidelines for the management of a pregnant trauma patient. J Obstet Gynaecol Can. 2015;37(6):553-74

88. $\mathrm{Ng} J$, Kitchen N. Neurosurgery and pregnancy. J Neurol Neurosurg Psychiatry. 2008;79:745-52.

89. Wang LP, Paech MJ. Neuroanesthesia for the pregnant woman. Anesth Analg. 2008;107:193-200.

90. Unterrainer AF, Steiner H, Kundt MJ. Caesarean section and brain tumour resection. Br J Anaesth. 2011;107:111-2.

91. Freo $U$, Pitton $M$, Carron M, Ori C. Anesthesia for urgent sequentia ventriculoperitoneal shunt revision and cesarean delivery. Int J Obstet Anesth. 2009;18:284-7.

92. Barr JJ. When death is not the end: continuing somatic care during postmortem pregnancy. Linacre Q. 2019;86:275-82.

93. Smok D, Prager KM. The ethics of neurologically complicated pregnancies. Handb Clin Neurol. 2020;171:227-42.

94. Esmaeilzadeh M, Dictus C, Kayvanpour E, Sedaghat-Hamedani F, Eichbaum M, Hofer S, Engelmann G, Fonouni H, Golriz M, Schmidt J, Unterberg A, Mehrabi A, Ahmadi R. One life ends, another begins: Management of a brain-dead pregnant mother-a systematic review. BMC Med. 2010;8:74.

95. Curiel-Balsera E, Prieto-Palomino MA, Muñoz-Bono J, Ruiz de Elvira MJ, Galeas JL, Quesada García G. Análisis de la morbimortalidad materna de las pacientes con preeclampsia grave, eclampsia y síndrome HELLP que ingresan en una Unidad de Cuidados Intensivos gineco-obstétrica Analysis of maternal morbidity and mortality among patients admitted to Obstetric Intensive Care with severe preeclampsia, eclampsia or HELLP syndrome. Med Intensiva 2011; 35: 478-483.

96. Kho GS, Abdullah JM. Management of severe traumatic brain injury in pregnancy: a body with two lives. Malays J Med Sci. 2018;25:151-7.

97. Yoshida K, Takahashi JC, Takenobu Y, Suzuki N, Ogawa A, Miyamoto S. Strokes associated with pregnancy and puerperium: a nationwide study by the Japan Stroke Society. Stroke. 2017:48:276-82.

98. Abalos E, Cuesta C, Grosso AL, Chou D, Say L. Global and regional estimates of preeclampsia and eclampsia: a systematic review. Eur J Obstet Gtnecol Reprod Biol. 2013;170:1-7.

99. Grear KE, Bushnell CD. Stroke and pregnancy: clinical presentation, evaluation, treatment, and epidemiology. Clin Obstet Gynecol. 2013;56:350-9. 